\title{
MicroRNA-34a Attenuates Paclitaxel Resistance in Prostate Cancer Cells via Direct Suppression of JAG1/Notch1 Axis
}

\author{
Xiaobing Liu ${ }^{\mathrm{a}}$ Xing Luo ${ }^{\mathrm{a}}$ Yuqi Wu ${ }^{\mathrm{a}}$ Ding Xia ${ }^{\mathrm{d}}$ Wei Chen \\ Zhenqiang Fang ${ }^{\mathrm{a}}$ Jianping Deng ${ }^{\mathrm{c}}$ Yaxing Hao $^{\mathrm{b}} \mathrm{Xia}$ Yang $^{\mathrm{b}}$ Teng Zhang ${ }^{\mathrm{a}}$ \\ Luqiang Zhou ${ }^{\mathrm{a}}$ Yingbing $\mathrm{Wu}^{\mathrm{a}}$ Qingqing Wang ${ }^{\mathrm{a}}$ Jie $\mathrm{Xu}^{\mathrm{a}}$ Xiaoyan $\mathrm{Hu}^{\mathrm{a}}$ \\ Longkun $\mathrm{Li}^{\mathrm{a}}$
}

aDepartment of Urology, Xinqiao Hospital, Third Military Medical University, Chongqing, 'Institute of Immunology, Third Military Medical University, Chongqing, 'Department of Urology, People's Liberation Army No. 458 Hospital, Guangzhou, 'Department of Urology, Tongji Hospital, Tongji Medical College, Huazhong University of Science and Technology, Wuhan, China

\section{Key Words}

miR-34a s • Chemoresistance $・$ Paclitaxel $•$ Prostate cancer • JAG1 • Notch1

\begin{abstract}
Background/Aims: Treatment options for metastatic castrate-resistant prostate cancer (mCRPC) are limited and typically centered on paclitaxel-based chemotherapy. In this study, we aimed to evaluate whether miR-34a attenuates chemoresistance to paclitaxel by regulating target genes associated with drug resistance. Methods: We used data from The Cancer Genome Atlas to compare miR-34a expression levels in prostate cancer (PC) tissues with normal prostate tissues. The effects of miR-34a inhibition and overexpression on PC proliferation were evaluated in vitro via Cell Counting Kit-8 (CCK-8) proliferation, colony formation, apoptosis, and cell-cycle assays. A luciferase reporter assay was employed to identify the interactions between miR34a and specific target genes. To determine the effects of up-regulation of miR-34a on tumor growth and chemo-resistance in vivo, we injected PC cells overexpressing miR-34a into nude mice subcutaneously and evaluated the rate of tumor growth during paclitaxel treatment. We examined changes in the expression levels of miR-34a target genes JAG1 and Notch1 and their downstream genes via miR-34a transfection by quantitative reverse transcription PCR (qRT-PCR) and western blot assay. Results: miR-34a served as an independent predictor of reduced patient survival. MiR-34a was down-regulated in PC-3PR cells compared with PC-3 cells. The CCK-8 assay showed that miR-34a overexpression resulted in increased sensitivity to paclitaxel while miR-34a down-regulation resulted in chemoresistance to paclitaxel in vitro. A study of gain and loss in a series of functional assays revealed that PC cells expressing miR-34a were chemosensitive. Furthermore, the overexpression of miR-34a increased the
\end{abstract} X. Liu, X. Luo, Y. Wu contributed equally to this work. 


\section{Cellular Physiology Cell Physiol Biochem 2018;50:261-276

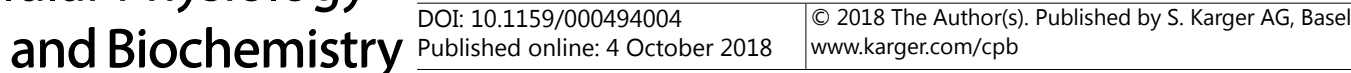

Liu et al.: microRNA-34a Attenuates Chemoresistance of Prostate Cancer Cells

sensitivity of PC-3PR cells to chemotherapy in vivo. The luciferase reporter assay confirmed that JAG1 and Notch1 were directly targeted by miR-34a. Interestingly, western blot analysis and GRT-PCR confirmed that miR-34a inhibited the Notch1 signaling pathway. We found that miR-34a increased the chemosensitivity of PC-3PR cells by directly repressing the TCF1/ LEF1 axis. Conclusion: Our results showed that miR-34a is involved in the development of chemosensitivity to paclitaxel. By regulating the JAG1/Notch1 axis, miR-34a or its target genes JAG1 or Notch1 might serve as potential predictive biomarkers of response to paclitaxelbased chemotherapy and/or therapeutic targets that will help to overcome chemoresistance at the MCRPC stage.

\section{Introduction}

Prostate cancer (PC) rates have risen rapidly in China over the last few years and PC is the most frequently diagnosed male carcinoma. In fact, rates in China are starting to catch up with those of western countries where this kind of cancer is one of the leading causes of death in men $[1,2]$. Current guidelines for the treatment of PC are based on the developmental stages of tumors. Surgery and radiation therapy are effective for early and localized cancers [3]. For metastatic castration-resistant prostate cancer (mCRPC), the standard first-line treatment is mainly taxane-based chemotherapy [4]. Paclitaxel and its related compound, docetaxel, both of which belong to the taxane family, show a median survival advantage of 2-3 months and improved quality of life compared with mitoxantrone [5, 6]. However, most patients eventually develop drug resistance, and those who benefit eventually die from the disease [4]. In this study, we attempted to explore the molecular mechanisms underlying the development of resistance to paclitaxel therapy in patients with PC.

MicroRNAs (miRNAs) are short, non-coding RNAs (-22 nucleotides) that binds to the 3'-untranslated region (3'-UTR) of mRNAs and modulate gene expression by controlling mRNA translation or degradation [7, 8]. Aberrant expression of miRNAs can cause a range of human disorders, especially malignant diseases. In fact, miRNAs act as either tumor suppressors or oncogenes in the development of a variety of malignancies in a tissue-specific manner. Moreover, they are broadly involved in tumor proliferation, invasion, angiogenesis, and drug resistance [9-12]. In recent studies, miRNAs, including miR-148a [12], miR-200c [13], miR-205 [13], miR-21 [14], miR-31 [3], miR-34 [15], and miR-375 [16], have been reported to regulate drug resistance in PC. miR-34a expression in tissue or circulation has been shown to potentially serve as a biomarker for PC diagnosis and prognosis $[17,18]$. To date, the biological role and the mechanism of action underlying miR-34a-mediated chemotherapeutic responses in MCRPC are not fully understood. A recent study on breast cancer showed that miR-34a is associated with response to paclitaxel treatment through the regulation of Notch1, which leads to the inhibition of stemness and partially increases chemosensitivity by down-regulating the Notch1 pathway [19]. The results suggested that miR-34a may be involved in the chemosensitivity of PC to the commonly used anti-cancer drug, paclitaxel.

We performed a series of in vitro and in vivo tests and found consistently lower expression of miR-34a in PC tissues and paclitaxel-resistant PC cells. Decreased miR-34a expression significantly increased the sensitivity of PC cells to paclitaxel treatment, as shown by the increased numbers of apoptotic cells. Furthermore, miR-34a overexpression in PC xenograft tumors after small interfering RNA transfection resulted in sensitivity to paclitaxel treatment. Finally, our data demonstrated that miR-34a may confer chemosensitivity to paclitaxel by reducing the levels of its targets, JAG1 and Notch1. These results indicated that miR-34a down-regulation is vital for the development and chemoresistance to PC, highlighting the potential of miR-34a as a therapeutic target. 


\section{Cellular Physiology Cell Physiol Biochem 2018;50:261-276

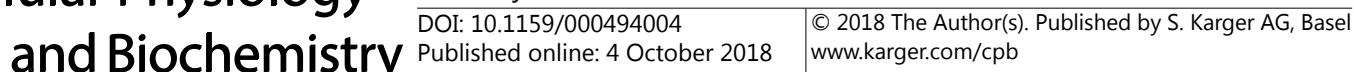

Liu et al.: microRNA-34a Attenuates Chemoresistance of Prostate Cancer Cells

\section{Materials and Methods}

\section{Protocol approval}

All experiments were carried out according to the guidelines for experiment research issued by the Third Military Medical University. The protocol was approved by the Institutional Animal Care and Use Committee of the Third Military University.

\section{Patients and samples}

The miR-34a expression profiles in PC tissues were obtained from The Cancer Genome Atlas (TCGA) database (https://tcga-data.nci.nih.gov and https://genome-cancer.ucsc.edu). The prognostic value of miR$34 \mathrm{a}$ was analyzed using the TCGA portal. Overall the survival of patients with high or low levels of miR-34a was demonstrated by a Kaplan-Meier survival plot.

\section{Cell culture and chemicals}

Human PC cell lines (PC-3 and PC-3PR) were purchased from the Shanghai Meixuan Biological Technology Company (Shanghai, China) and cultured in RPMI 1640 media with $10 \%$ fetal bovine serum, penicillin, and streptomycin (Gibco, Carlsbad, CA, USA). The cell lines were maintained at $37^{\circ} \mathrm{C}$ and $5 \% \mathrm{CO}_{2}$ in a humidified incubator. Paclitaxel was purchased from the Cayman Chemical Company (Ann Arbor, MI, USA). Cancer cell lines PC-3 and PC-3PR were seeded in 6-well plates at $3 \times 10^{5}$ per well, incubated overnight, and treated with paclitaxel for a further $48 \mathrm{~h}$. After induction, the cells were harvested for subsequent analysis.

The miR-34a mimic and miR-34a inhibitor were obtained from RiboBio (Guangzhou, China). Primary antibodies against GAPDH and JAG1, ADAM17, Notch1, NICD, Bcl2, Cyclin D1, CDK6, and c-MYC protein were obtained from Cell Signaling Technology (Danvers, MA, USA).

\section{Quantitative real-time polymerase chain reaction}

Total RNA was extracted from harvested cells using the Cell Counting Kit-8 (CCK-8, Dojindo Molecular Technologies Inc., Kumamoto, Japan) according to the manufacturer's instructions. As previously described, quantitative reverse transcription PCR (qRT-PCR) was conducted to detect miRNA-34a, ADAM17, JAG1, Notch1, c-MY, cyclin D1, CCDK6, and E-cadherin [20]. The Reverse SYBR Green PCR Kit (Invitrogen, Carlsbad, CA, USA), required $1 \mu \mathrm{g}$ of total RAN per sample to covert to cDNA. The cDNAs were then amplified and detected via the SYBR Green PCR kit (Qiagen, Valencia, CA, USA). GAPDH was used as an endogenous control for mRNA. The cDNA products were synthesized using miScript, reverse transcription kit (Qiagen) to detect mRNA, and the primers specific to miR-34a, or endogenous control U6, were purchased from Qiagen. qRTPCR was performed using miScript SYBR Green PCR Kit (Qiagen). All reactions were run in triplicate on a Bio-Rad C1000 thermal cycler (CFX-96 real-time PCR detection systems, Bio-Rad, Hercules, CA). The fold change in miRNA for mRNA expression were calculated using the $2^{-\Delta \Delta c t}$ method. The sequences of all primers are given in Table 1.

\section{MiRNA qRT-PCR}

Total RNA was extracted as described previously. Targetspecific reverse transcription and the TaqMan microRNA assay were carried out using the Hairpinit miRNA qPCR Quantitation Kit (Ribo, Guangzhou, China) according to the manufacturer's instructions. Reactions were performed using the 7500 Real-Time PCR System (Applied Biosystems, Waltham, MA). All primer sequences are provided in Table 1. The expression
Table 1. Nucleotide sequences of primers used for qRT-PCR reactions

\begin{tabular}{|c|c|c|}
\hline Gene & Forward & Reverse \\
\hline$\overline{\text { GAPDH }}$ & $5^{\prime}$ - TCAAGAAGGTGGTGAAGCAGG - $3^{\prime}$ & ' ${ }^{\prime}$ - TCAAAGGTGGAGGAGTGGGT - $3^{\prime}$ \\
\hline ADAM 17 & 5'- GGCCCAGGAGTGTTTTCAAG -3' & 5'- ACTGTTCCTGTCACTGCACT -3' \\
\hline JAG1 & 5'- CACACCTGAAAGACCACTGC -3' & 5'- CATGGCAGTATGTTCCCGTG -3’ \\
\hline NOTCH1 & 5'- CCCTGAATTTCACTGTGGGC - $3^{\prime}$ & 5'- GCCCTGGTAGCTCATCATCT -3’ \\
\hline cyclin D1 & 5'- ACAGATCATCCGCAAACACG -3' & 5‘- GGCGGTAGTAGGACAGGAAG -3' \\
\hline CDK6 & 5'- TGTTTCAGCTTCTCCGAGGT -3' & 5'- TATGCAGCCAACACTCCAGA -3' \\
\hline $\mathrm{Bcl} 2$ & 5'-TTGGGGACAAGGGCTCTAAA-3' & 5'-AGAATGTTGGCGTCTTGTTTGA-3' \\
\hline E-cadherin & n 5'- CGTAGCAGTGACGAATGTGG -3' & 5'- CTGGGCAGTGTAGGATGTGA -3' \\
\hline $\operatorname{miR}-34 a$ & 5'-TGGCAGTGTCTTAGCTGG-3' & \\
\hline U6 & 5'-CTTCGGCAGCACATATAC-3' & 5'-GAACGCTTCACGAATTTGC-3' \\
\hline
\end{tabular}




\section{Cellular Physiology Cell Physiol Biochem 2018;50:261-276 \\ \begin{tabular}{ll|l} 
DOI: 10.1159/000494004 & $\begin{array}{l}\text { O 2018 The Author(s). Published by S. Karger AG, Basel } \\
\text { www.karger.com/cpb }\end{array}$ \\
\hline
\end{tabular}}

Liu et al.: microRNA-34a Attenuates Chemoresistance of Prostate Cancer Cells

of miR-34a was normalized to small nuclear RNA $u 6$, and relative expression was calculated using the $2^{-\Delta \Delta c t}$ method. All procedures were performed in triplicate.

\section{Oligonucleotide transfection}

For transient transfection, miRNA mimics and inhibitors were transfected into PC-3 and PC-3PR cells using Lipofectamine RNAiMAX Reagent (Invitrogen) following the manufacturer's protocol. The miR34a mimic, inhibitor, and negative controls were obtained from RiboBio (Guangzhou, China). The final concentrations of miR-34a mimic; inhibitor, and negative control in the transfection system were each 200 nM. After $48 \mathrm{~h}$, cells were collected for subsequent flow cytometry, western blotting, and qRT-PCR.

\section{Cell proliferation assay}

Cell proliferation was evaluated via CCK-8 as described by the manufacturer (Dojindo Molecular Technologies, Inc.). Cells (5000 PC-3 or P-3PR per well) were cultured in 96-well plates overnight, and $10 \mu \mathrm{L}$ of CCK-8 solution was added to each well at the indicated time points after transfection. Cells were further incubated for $2 \mathrm{~h}$ at $37^{\circ} \mathrm{C}$ in a $5 \% \mathrm{CO}_{2}$ incubator. The absorbance was measured at $450 \mathrm{~nm}$ with a Multiscan FC Microplate Photometer (Thermo Fisher Scientific, Rochester, NY, USA).

\section{Clone formation assay}

Six groups of transfection PC cells were plated in 6-well plates (500 cells/well) and cultured in RPMI1640 medium for 14 days. Proliferation colonies were stained with crystal violet, and colonies consisting of 50 cells or more were counted and photographed for statistical analysis. All procedures were performed in triplicate.

\section{Western blotting}

Cells were lysed in RIPA buffer (1\% NP-40, $0.5 \%$ sodium deoxycholate, $0.1 \%$ sodium dodecyl sulfate [SDS] in phosphate-buffered saline [PBS]). A complete protease inhibitor cocktail (Roche Diagnostics, Indianapolis, IN, USA) was added to the lysis buffer before use. Protein concentration was determined by a Bio-Rad DC protein assay (Bio-Rad). We transferred $30 \mu \mathrm{g}$ of total protein from cell lysates subjected to SDS-polyacrylamide gel electrophoresis to nitrocellulose membrane. The membrane was blocked in 5\% non-fat milk in PBS overnight and incubated with primary antibodies. After washing for $30 \mathrm{~min}$, secondary goat ant-mouse IgG (Vector Laboratories Inc., Burlingame, CA, USA) was applied to nitrocellulose membranes in tri-buffered saline with Tween 20 for $1 \mathrm{~h}$. After washing, targeted proteins were detected using Chemiluminescent HRP Antibody Detection Kit (Denville Scientific, South Plainfield, NJ, USA). Protein signals were captured with an electrochemiluminescent system (PerkinElmer Life Sciences, Boston, MA, USA).

\section{Apoptosis assay}

Cell apoptosis was detected using Annexin V-PE Apoptosis Detection Kit (BD Pharmingen, San Jose, CA USA). Cells in the logarithmic phase of growth were harvested and washed twice in PBS and, according to the manufacturer's instructions, $1 \times 10^{6}$ cells were washed twice in PBS before re-suspension in a $1 \times$ binding buffer. PE Annexin V $(5 \mu \mathrm{L})$ and 7-AAD $(5 \mu \mathrm{L})$ were added and the cells remained there for $30 \mathrm{~min}$, after which $400 \mu \mathrm{L}$ of $1 \times$ binding buffer was added to each tube. Stained cells were measured by flow cytometry (FACSCalibur, BD Biosciences, Heidelberg, Germany) using Cell Quest Pro software (BD Biosciences). Data were analyzed using FlowJo 10 software (BD Biosciences, Heidelberg, Germany).

Cell cycle assay

A total of $1 \times 10^{6}$ cells fixed using $70 \%$ ethanol at $-20^{\circ} \mathrm{C}$ were incubated with propidium iodide (Invitrogen) for $30 \mathrm{~min}$ at $37^{\circ} \mathrm{C}$ and then analyzed using fluorescence-activated cell sorting flow cytometry (BD Biosciences).

\section{Luciferase Reporter Assay}

In brief, 3' UTR segments of JAG1 and Notch1 were predicted to interact with miR-34a (https://www. targetscan.org). The luciferase reporter was successfully constructed by molecular cloning technology. Targeted sequences were inserted into pGL3-Basic vector (Promega Corp., Madison, WI, USA), to obtain 


\section{Cellular Physiology Cell Physiol Biochem 2018;50:261-276 \begin{tabular}{ll|l} 
DOI: 10.1159/000494004 218 and Biochemistry & $\begin{array}{l}\text { O } 2018 \text { The Author(s). Published by S. Karger AG, Basel } \\
\text { www.karger.com/cpb }\end{array}$ \\
\cline { 2 - 4 }
\end{tabular}}

Liu et al.: microRNA-34a Attenuates Chemoresistance of Prostate Cancer Cells

pGL3-JAG1-3'-UTR and pGL3-Notch1-3'-UTR, containing the miR-34a binding sequences (JAG1-3'-UTR and Notch1-3'-UTR sequences). The miR-34a modified cells were seeded in 24 -well plates for $24 \mathrm{~h}$ and then they were transfected with $1 \mu \mathrm{g}$ of luciferase-reporter plasmids per well using PEI Transfection Reagent. Afterwards, according to the manufacturer's instructions, luciferase activities were measured using the dual-luciferase reporter gene assay kit (Promega).

In vivo tumor xenograft model

We used five-week-old female athymic nude mice for these experiments. Animals were housed with wood chip bedding in an environmentally-controlled-room with clean air, a 12-h light-dark cycle, and a relative humidity of $50 \%$. Drinking water and a standard diet were supplied ad libitum. The study was approved by the Institutional Animal Care and Use Committee at the Third Military Medical School.

The mice were inoculated subcutaneously with PC-3, PC-3PR, and PC-3PR and transfected with miR34 a mimic $(n=8)$. Xenografts were inoculated with $2 \times 10^{6}$ cells suspended in $100 \mu \mathrm{LBS}$ with $50 \%$ Matrigel (BD Biosciences). When tumors reached an average volume of $100 \mathrm{~mm}^{3}$, mice were randomly assigned to a control group (0.5\% DMSO in PBS), or 10 mg/kg.bw paclitaxel (Cayman Chemicals, Ann Arbor, MI, USA). The treatment was administered every third day. The mice were weighed, and tumor volumes were measured twice a week with a digital caliper (volume $=\pi / 6 \times$ width $^{2}$ ). After 3 weeks, the mice were sacrificed; and tumor weights were measured. For lung and liver metastasis experiments, we generated PC lung and liver metastatic models by injecting PC cells through the tail veins. We suspended $5 \times 10^{5}$ of the indicated cells in $0.1 \mathrm{~mL}$ of PBS and injected them into the lateral tail veins of 6-week-old female nude mice (8 mice per week). Six-weeks after the injections, all mice were sacrificed, and the lung and liver surface tumor foci were counted.

\section{Immunohistochemistry}

Tumor specimens from nude mice were fixed in $4 \%$ paraformaldehyde and embedded in paraffin. The paraffin-embedded tissue blocks were cut into 4- $\mu$ m slides. Sections were used for the analysis of Ki67 protein (1:100, Cell Signaling Technology). The samples were incubated at $4^{\circ} \mathrm{C}$ overnight with primary antibodies against Ki67 and finally treated with secondary antibody for $30 \mathrm{~min}$ and stained with diaminobenzidine until brown granules appeared.

Terminal deoxynucleotidyl transferase dUTP nick end labeling assay

The terminal deoxynucleotidyl transferase dUTP nick end labeling (TUNEL) assay was performed to detect apoptotic cell death in xenograft tumors using DeadEnd ${ }^{\mathrm{TM}}$ Colorimetric TUNEL System (Promega). Slides were prepared according to the manufacturer's instructions.

\section{Statistical analysis}

All data are expressed as the mean \pm SD unless otherwise stated. Comparisons between two groups were performed using a two-tailed unpaired t-test. Comparisons between three or more groups were performed using one-way analysis of variance (ANOVA). The differences between tumor volumes were determined via a two-way ANOVA. Overall survival analysis was performed using the Kaplan-Meier method. $\mathrm{P}<0.05$ was considered statistically significant.

\section{Results}

miR-34a is associated with overall survival and is decreased by paclitaxel in PC cell lines

Since some of these patients in the cohort had received paclitaxel chemotherapy, we wanted to see if miR-34a was involved in the development of resistance to paclitaxel and whether it would have an impact on overall survival. We first compared the expression levels of patients with miR-34a at different stages of PC patients to a TCGA dataset. The expression levels of miR-34a were lower in the late stages of the disease than in the early stages, indicating that miR-34a is a tumor suppressor in PC (Fig. 1A). Furthermore, to investigate the role of miR-34a in PC overall survival, Kaplan-Meier survival analysis demonstrated that PC patients with low levels of miR-34a had lower survival rates compared with those with 
Fig. 1. Down-regulated expression of miR-34a in PC tissues correlated with tumor progression. (A) Levels of miR-34a in prostate cancer patients at different stages compared with early stage subjects in the TCGA database. (B) Kaplan-Meier analysis of overall survival in patients with PC with low and high miR-34a levels. (C) miR$34 \mathrm{a}$ levels in PC-3_and PC-3PR cells. (D) miR-34a levels in PC-3, PC-3 miR34a inhibitor, PC-3PR, and PC-3PR miR-34a mimic groups. ${ }^{*} \mathrm{p}<0.05$; ${ }^{* *} \mathrm{p}<0.01$; $* * * \mathrm{p}<0.001$.

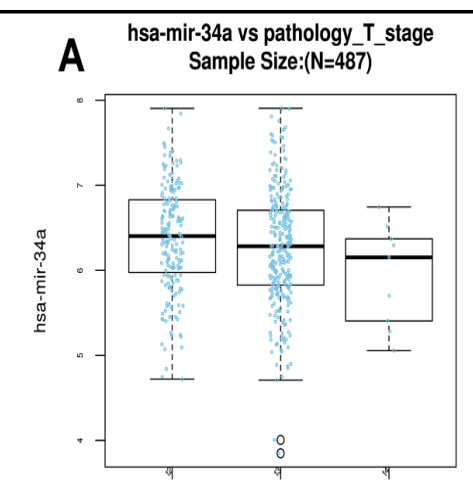

\section{B}
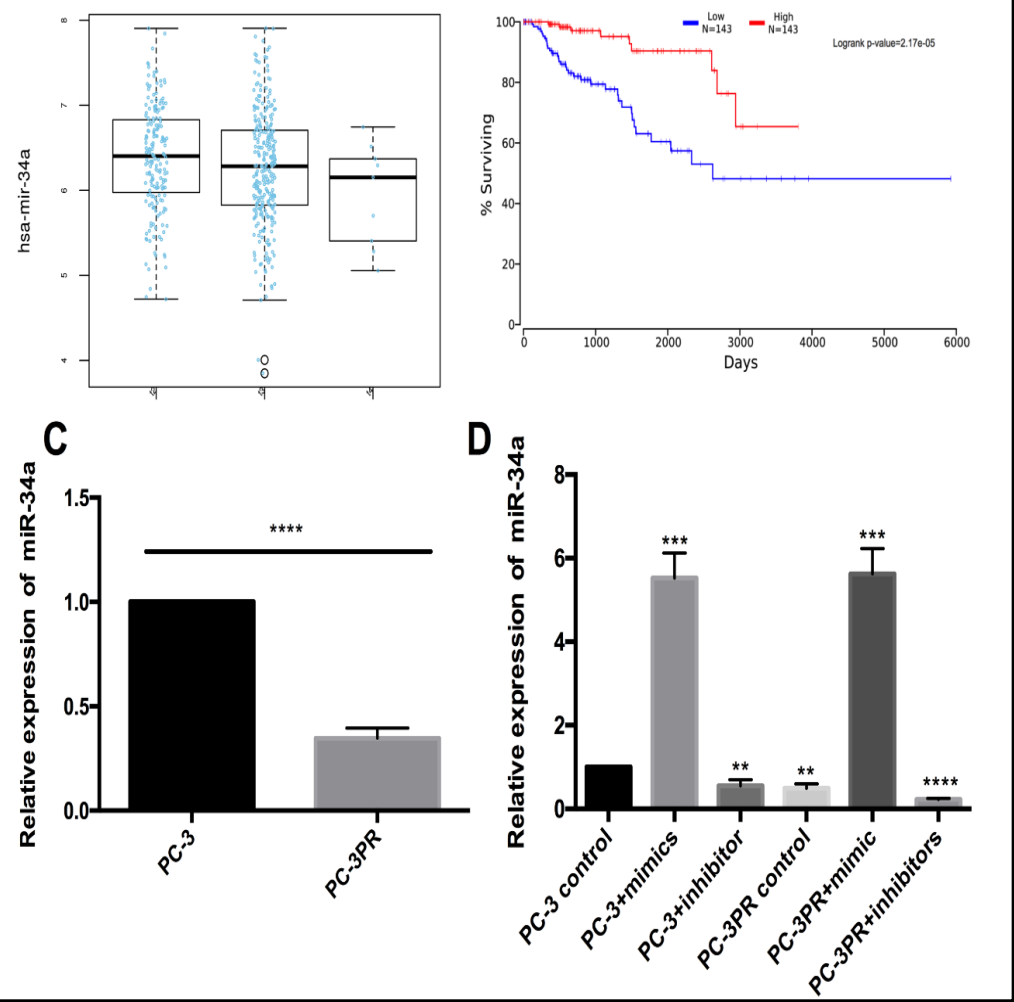

high miR-34a levels (Fig. 1B). To further study the impact that paclitaxel chemotherapy had on the expression of miR-34a in PC cells, we tested PC-3 and PC-3PR cells with paclitaxel. qRT-PCR analysis showed that miR-34a expression was significantly decreased in PC3PR cells compared with PC-3 cells (Fig. 1C). Taken together, these results suggested that the decreased expression of miR-34a indicated a poor prognosis could be involved in the stimulation of PC chemo-resistance.

miR-34a contributes to paclitaxel resistance in PC cell lines

As shown in Fig. 1D, qRT-PCR analysis confirmed high levels of expression of miR34a after miR-34a mimic transfection, along with low levels of expression in miR-34a inhibitor transfection in PC-3 and PC-3PR cells. We determined the effect of miR-34a on the proliferation in PC cell lines PC-3 and PC-3PR by transfecting them with miR-34a inhibitors and miR-34a mimics, respectively. The proliferation rate of the miR-34a mimic group cells $48 \mathrm{~h}$ after transfection was significantly lower than that of the miRNA negative control and miR-34a inhibitor groups of cells, and higher in a control group of PC-3 and PC-3PR cells (Fig. 2A and 2B). Colony formation assays obtained similar results (Fig. 2C, 2D, and 2E) and morphological analysis of the cells showed a similar change in the cells, characterized by cell volume and concomitant shrinking (Fig. $2 \mathrm{~F}$ ).

To evaluate the involvement of miR-34a in the regulation of sensitivity to paclitaxel, we transfected a miR-34a mimic and miR-34a inhibitor into PC cell lines. We conducted an apoptosis assay via flow cytometry to determine whether the effects of miR-34a on cell proliferation were related to apoptosis. We transfected PC cells with miR-34a mimic and miR$34 \mathrm{a}$ inhibitor for $24 \mathrm{~h}$ and then treated the cells with paclitaxel for another $24 \mathrm{~h}$. Our results showed that ectopic overexpression of miR-34a increased paclitaxel-induced apoptosis, 


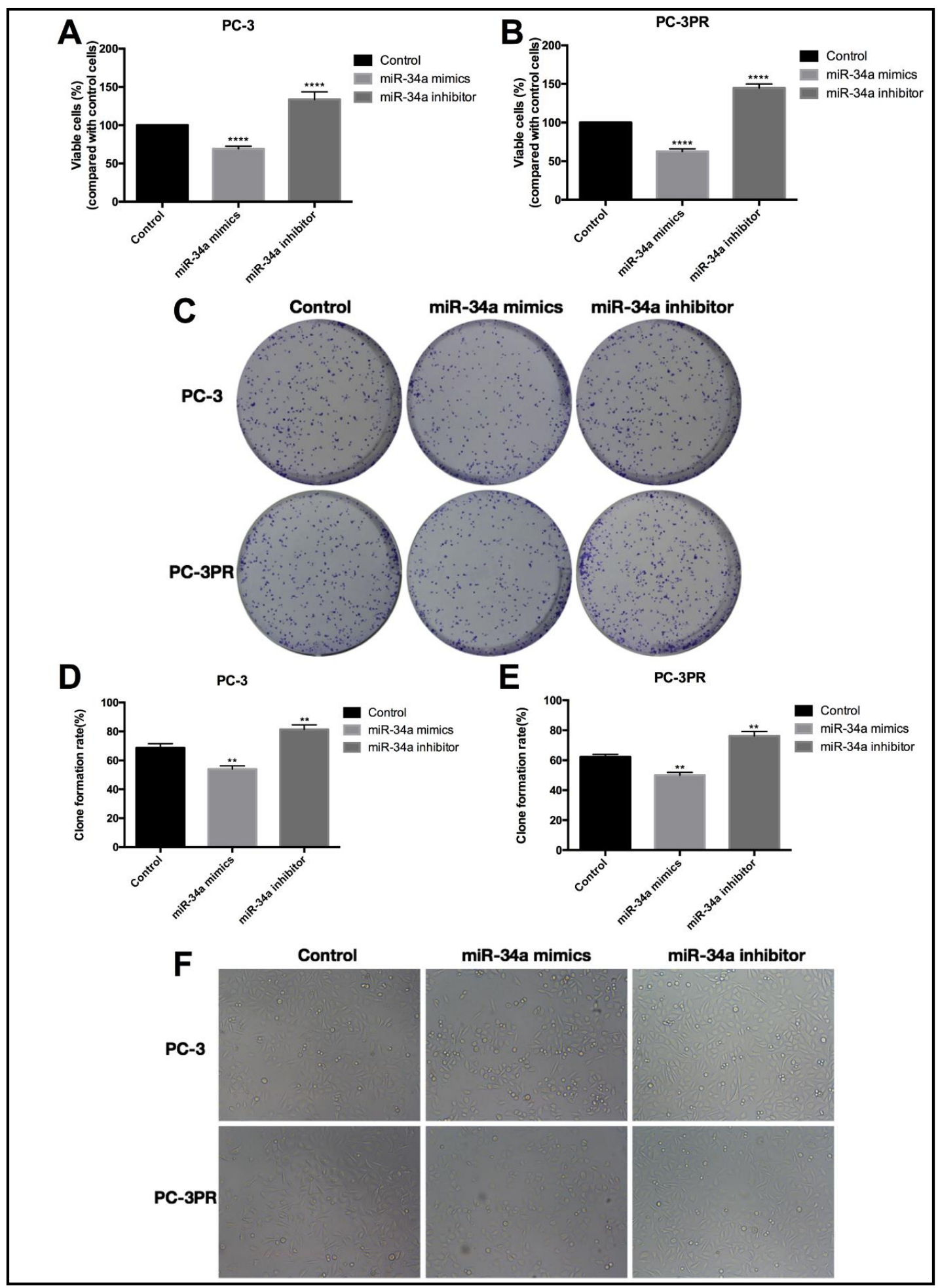

Fig. 2. miR-34a attenuated PC proliferation in vitro(A) Overexpression of miR-34a reduced the paclitaxelinduced inhibition of cell growth, with simultaneous inhibition of miR-34a cell growth increases in PC-3 cells. (B) Overexpression of miR-34a reduced paclitaxel-induced cell growth inhibition; conversely, inhibition of miR-34a increased cell growth in PC-3PR cells. (C, D, E) Overexpression of miR-34a reduced the formation of PC cell clones, and inhibition increased formation. (F) Morphological analysis of the PC cells with inhibition vs overexpression. ${ }^{*} \mathrm{p}<0.05 ;{ }^{* *} \mathrm{p}<0.01 ;{ }^{* * *} \mathrm{p}<0.001$.

\section{KARGER}




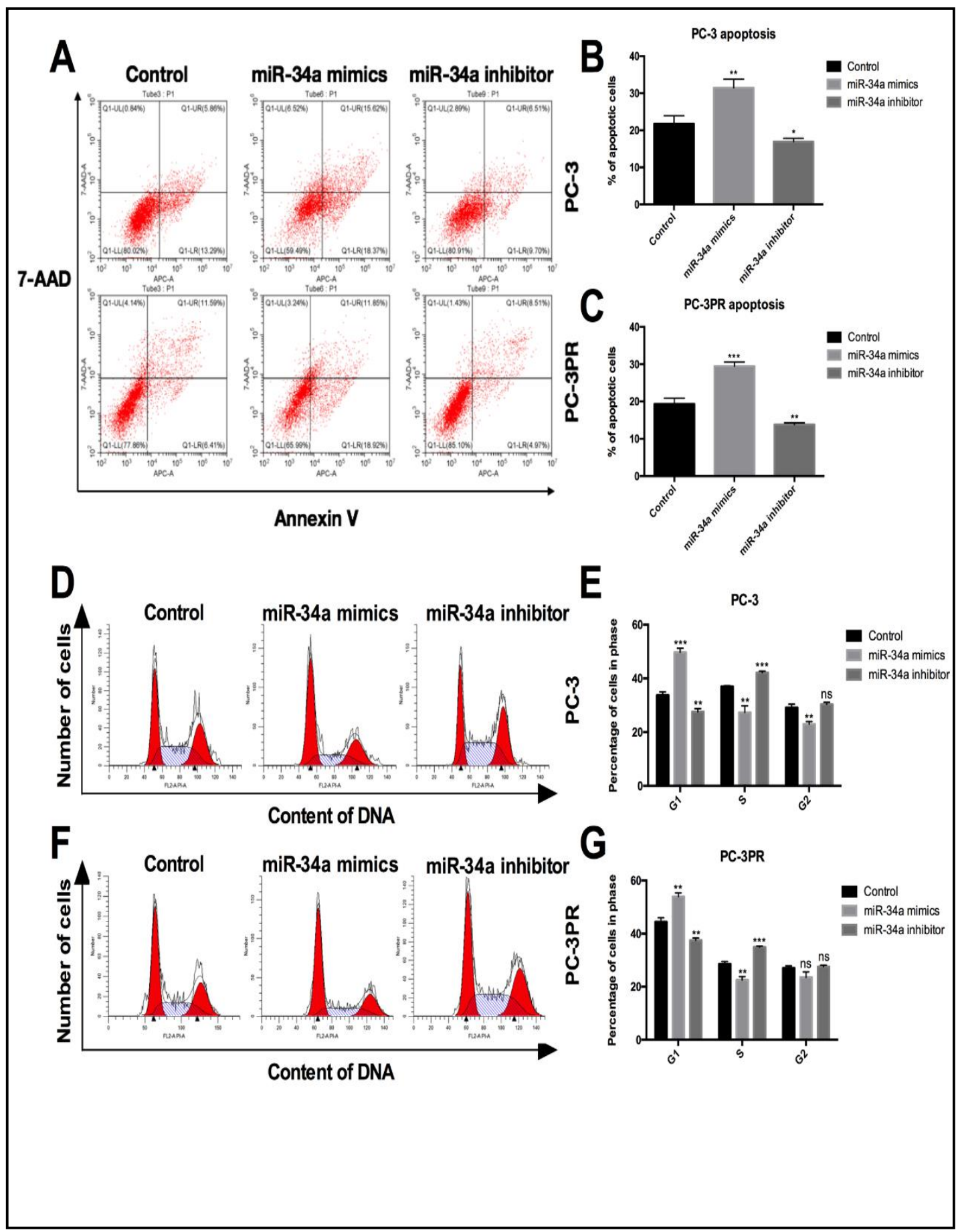

Fig. 3. miR-34a attenuated chemo-resistance in PC cells(A, B, C) Flow cytometry analysis showed that low levels of miR-34a protected cells from apoptosis in PC-3 and PC-3PR cells, while it showed that high levels of miR-34a promoted cell apoptosis in PC-3 and PC-3PR cells. (D, E) Cell cycle assays showed that low levels of miR-34a promoted the cell cycle through reduced G1/G0 arrest, while they showed that high levels of miR34a induced G1/G0 arrest in PC-3 cells. (F, G) Cell cycle assays showed that low levels of miR-34a promoted the cell cycle through reduced G1/G0 arrest, while they showed that high levels induced G1/G0 arrested PC-3PR cells. ${ }^{*} \mathrm{p}<0.05 ;{ }^{* *} \mathrm{p}<0.01 ;{ }^{* * *} \mathrm{p}<0.001$. 
while miR-34a inhibition decreased miR-34a-induced apoptosis in PC-3 cells (Fig. 3A and 3B). Similar data were also observed in PC-3PR cells (Fig. 3A and 3C). Thus, to determine whether the effects of miR-34a on cell proliferation were related to the cell cycle, we first transfected PC cells with miR-34a inhibitor for $24 \mathrm{~h}$ and then treated the cells with paclitaxel for another $24 \mathrm{~h}$. Our results showed that miR-34a overexpression induced G1/G0 arrest, while miR-34a inhibition promoted the cell cycle in PC-3 and PC-3PR cells (Fig. 3D, 3E, 3F, and $3 \mathrm{G}$ ). Based on these findings, we thought that PC cells with miR-34a down-regulation were resistant to paclitaxel treatment.

miR-34a inhibits PC chemo-resistance through direct suppression of JAG1 and Notch1 expression

In order to investigate the underlying mechanism of the effects of miR-34a on PC, we used miRNA target prediction algorithms (http://targetscan.org) to screen miR-34a target genes. We identified JAG1 and Notch1 as tentative targets of miR-34a (Fig. 4C and 5C) because previous studies have shown that the Notch 1 signaling pathway correlates closely with PC progression, metastasis, and chemoresistance [21,22]. Furthermore, sequence alignment of the predicted miR-34a showed high conservation among different species. The sequences

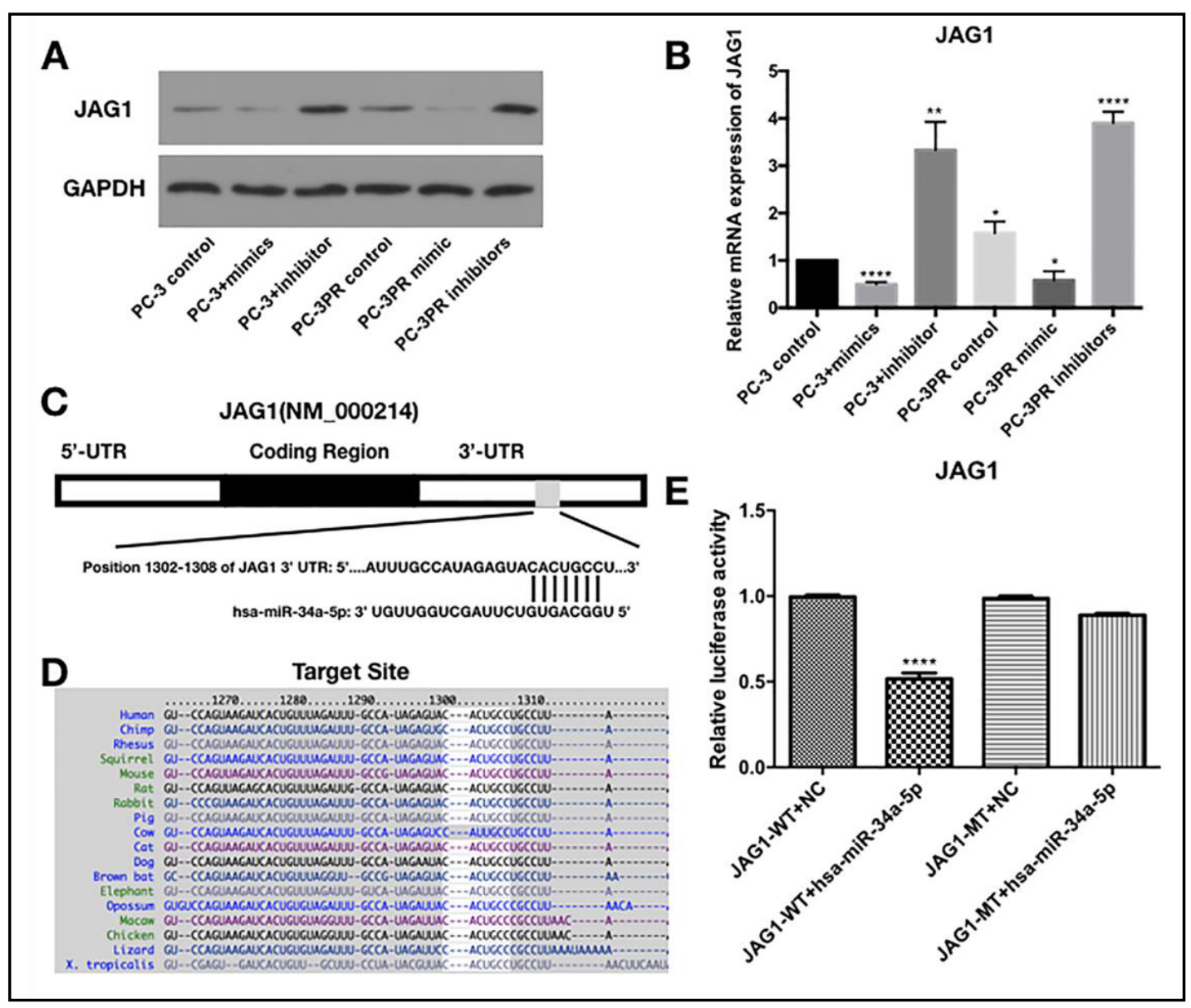

Fig. 4. miR-34a inhibited $\mathrm{BC}$ chemo-resistance by directly regulating JAG1 expression (A). Western blot for JAG1 expression in PC-3 and PC-3PR cells. (B) qRT-PCR for JAG1 mRNA expression in PC-3 and PC-3PR cells. (C) Predicted binding site of miR-34a in 3'-UTR of human JAG1 mRNA. (D) Sequence alignment of the predicted binding site of miR-34a showed high conservation among different species. The sequences of miR-34a target sites in JAG1 3'-UTR are underlined. (E) miR-34a modified PC-3 cells were transfected with $1 \mu \mathrm{g}$ of JAG1'UTR luciferase-reporter plasmids, and luciferase activities were quantified. ${ }^{*} \mathrm{p}<0.05$; ${ }^{* *} \mathrm{p}<0.01$; $* * * \mathrm{p}<0.001$. 


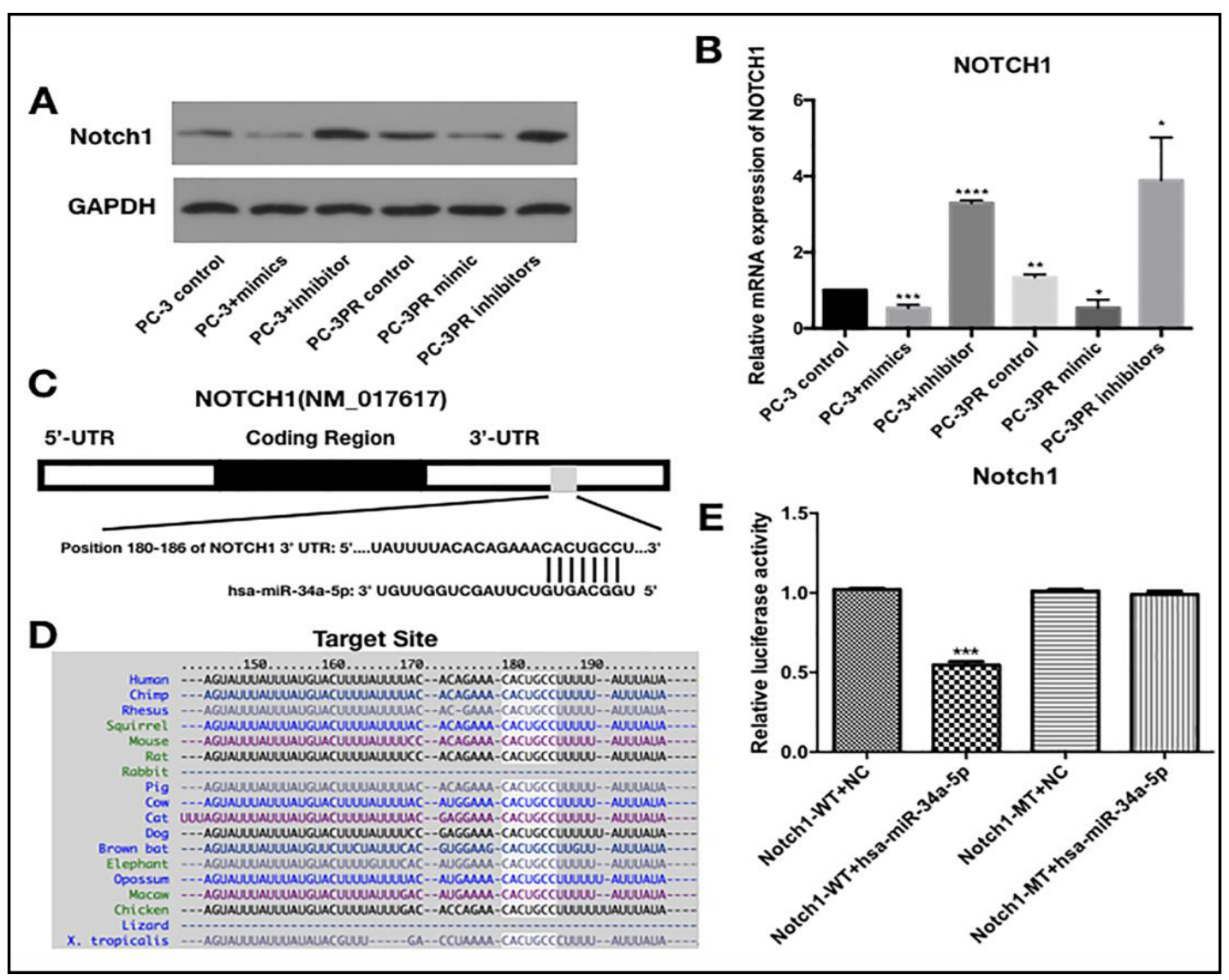

Fig. 5. miR-34a inhibited $B C$ chemo-resistance through direct regulation of Notch1 expression(A) Western blots for Notch1 expression in PC-3 and PC-3PR cells. (B) qRT-PCR for Notch1 mRNA expression in PC-3 and PC-3PR cells. (C) Predicted binding site of miR-34a in 3'-UTR of human JAG1 mRNA. (D) Sequence alignment of the predicted binding sites of miR-34a showed high conservation among different species. The sequences of miR-34a target sites in JAG1 3'-UTR are underlined. (E) miR-34a modified PC-3 cells were transfected with $1 \mu \mathrm{g}$ of Notch1'UTR luciferase-reporter plasmid, and the luciferase activities were quantified. ${ }^{*} \mathrm{p}<0.05$; ${ }^{* *} \mathrm{p}<0.01 ;{ }^{* * *} \mathrm{p}<0.001$.

of miR-34a target sites in JAG1 3'-UTR and Notch1 3'-UTR are underlined (Fig. 4D and 5D).

To investigate whether miR-34a directly regulates JAG1/Notch1 expression, we examined the expression levels of JAG1 and Notch1 in miR-34a overexpressing and nonexpressing PC-3 and PC-3PR cells at both the mRNA and protein levels, respectively (Fgi.4A, 4B and 5A, 5B). The results indicated that miR-34a inhibited JAG1 and Notch1 expression. Moreover, by using western blot and qRT-PCR analysis, we found that miR-34a negatively regulated Notch1 downstream genes, including those of cleaved-caspase3, Bcl2 (Fig. 6A and 6B), Cyclin D1 (Fig. 6A and 6C), CDK6 (Fig. 6A and 6D), and ADAM17 (Fig. 6A).

Furthermore, to determine whether the regulation of JAG1-luciferase expression and Notch1-luciferase expression depended on the binding of complementary 3'UTR sequences to the miR-34a seed sequence, we inserted a 3-nt mutation into the JAG1 3'UTR and Notch1 3'UTR, as indicated in Fig. 4C and 5C. In addition, the mutations are located in regions of JAG1 and Notch1 that are conserved across different species (Fig. 4D and 5D). Our data showed that overexpression of miR-34a significantly repressed luciferase activity associated with wild-type 3'UTR, while the 3'UTR mutation completely abrogated the effect of miR-34a overexpression on luciferase activity in PC-3 cells (Fig. 4E and 5E).

Taken together, these data suggested that miR-34a directly repressed JAG1/Notch1 axis by targeting the 3'UTR sequence. 
JAG1/Notch1 axis
is associated with
poor prognosis in $P C$
tissues

To evaluate the role of JAG1 and Notch1 in overall survival and disease-free survival in patient-derived PC tissues, KaplanMeier survival analysis demonstrated that PC patients with high levels of JAG1 had low overall survival rates compared with those with a low level of JAG1 in disease-free survival via TCGA data (Fig. 7A, 7B, 7C, and 7D). We performed correlation analysis between the expression levels of JAG1 and Notch1. This analysis demonstrated that the levels of JAG1 and Notch1 correlated positively $(\mathrm{r}=0.24$ for JAG1 and Notch1, $\mathrm{p}<0.05)$ (Fig. 7E). Furthermore, TCGA data revealed the expression of Notch1 signaling; Hey1, Hey2, and Myc were up-regulated in tumor tissues compared with normal tissues, while NUMB, FBXW7, and CDH1 were downregulated in tumor tissues compared with normal tissues (Fig. 7F). Collectively, these data from clinical samples in PC patients indicated the relevancy of the inhibitory effects of JAG1 and Notch1.

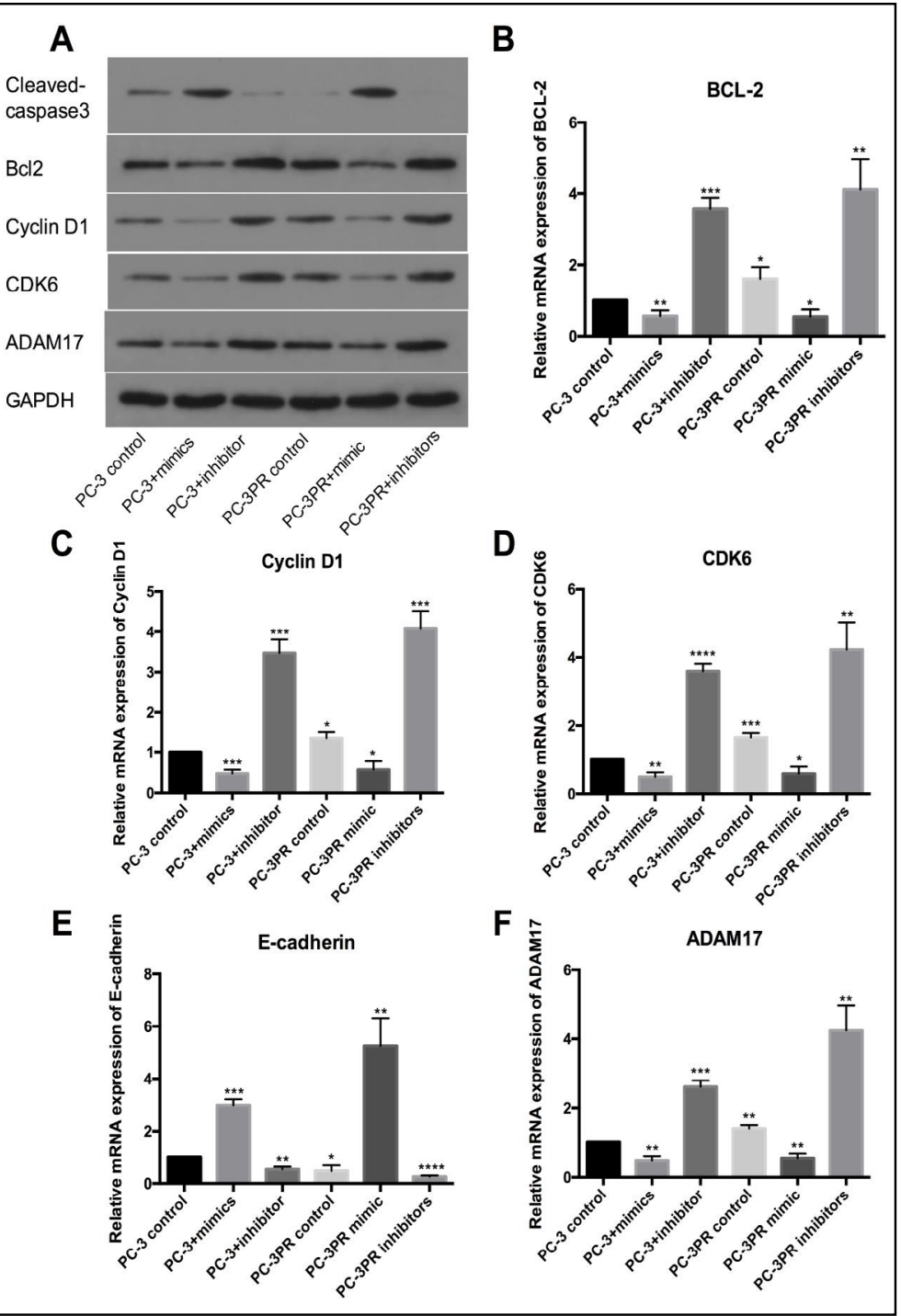

Fig. 6. miR-34a negatively regulated Notch 1 signaling pathway(A) Western blots of Notch1 signaling pathways in PC-3 and PC-3PR cells. (B) qRT-PCR for Bcl2 mRNA expression. (C) qRT-PCR for CDK6 mRNA expression. (D) qRT-PCR for cyclin D1 mRNA expression. (E) qRT-PCR for E-cadherin mRNA expression. (F) qRT-PCR for ADAM17 mRNA expression. ${ }^{*} \mathrm{p}<0.05$; ${ }^{* *} \mathrm{p}<0.01 ;{ }^{* * *} \mathrm{p}<0.001$. 


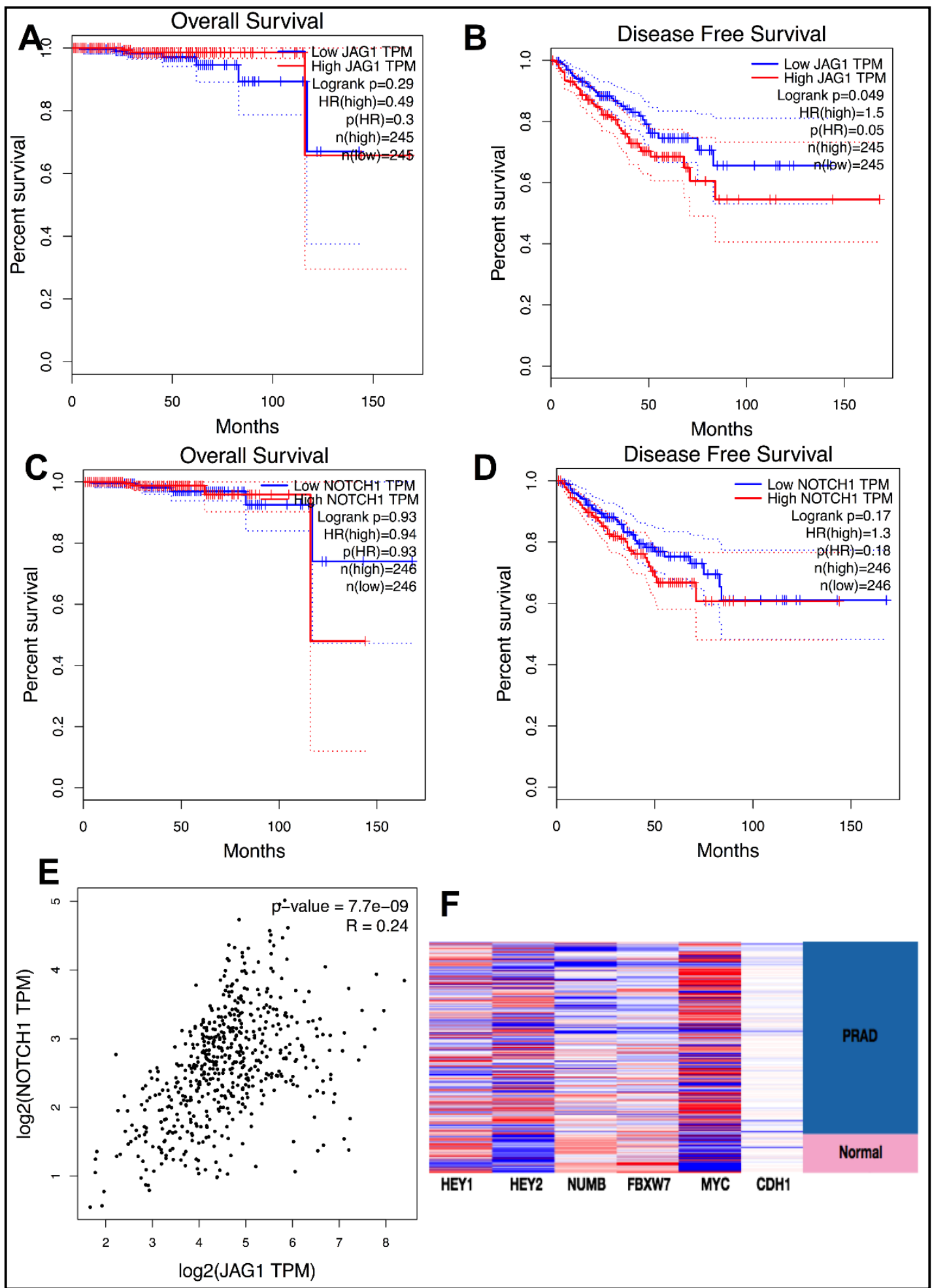

Fig. 7. The JAG1/Notch1 axis was associated with and suggested a poor prognosis among PC tissues(A) Overall survival of JAG1 in PC patients. (B) Disease-free survival of JAG1 in PC patients. (C) Overall survival of Notch1 in PC patients. (D) Disease-free survival of Notch1 in PC patients. (E) Correlation between JAG1 and Notch1 according to TCGA data. (F) Gene expression of Notch1 signaling pathway among the TCGA data. 


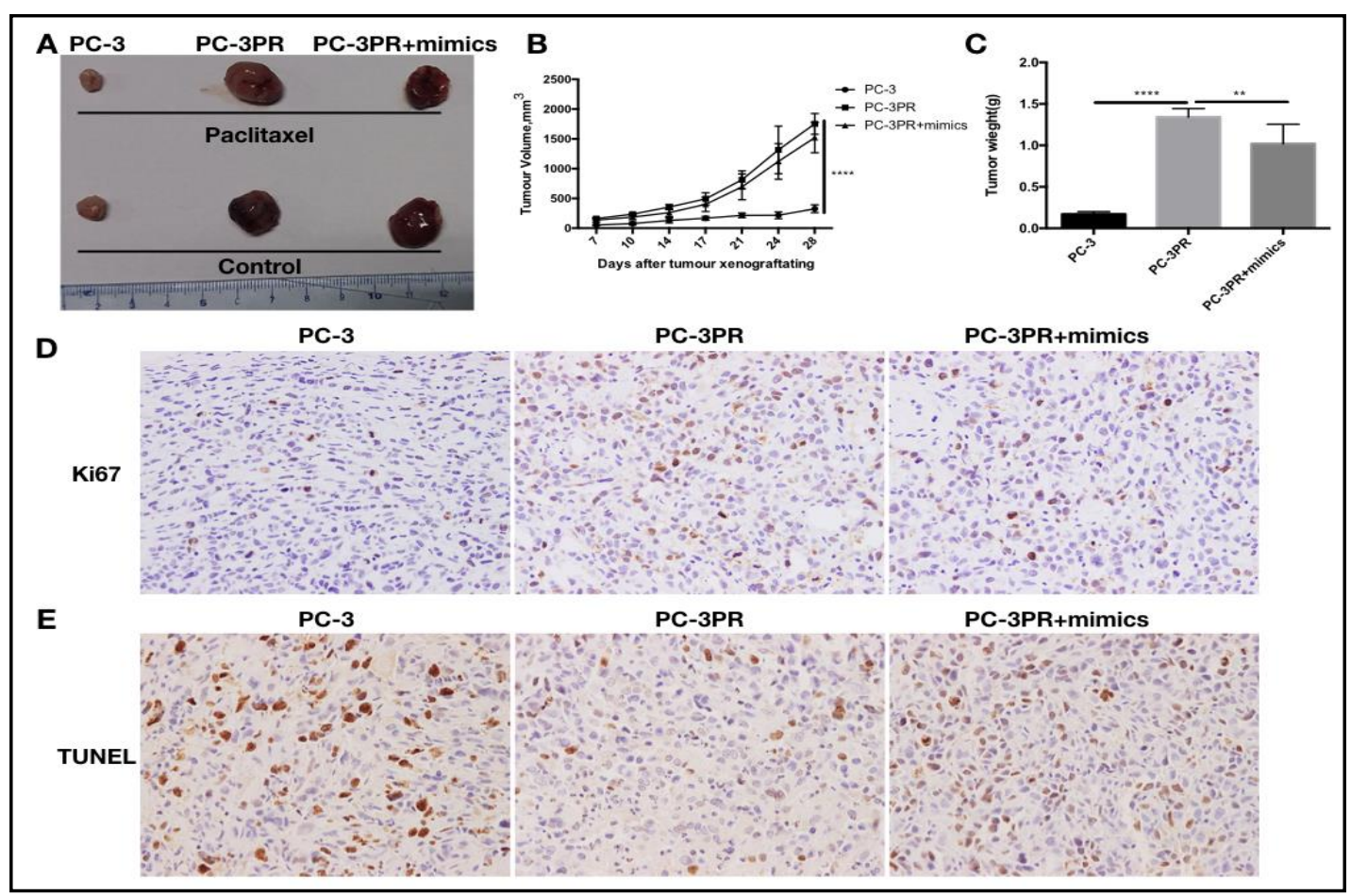

Fig. 8. miR-34a attenuated PC chemoresistance and metastasis (A) Xenografts with PC-3PR were significantly larger than in the miR-34a overexpression and PC-3 groups. Representative tumors from each group are shown. (B) Tumor volumes in the paclitaxel-treated mice increased with time, particularly xenografts tumors in PC-3PR cells. (C) Tumor weights at the end of the treatment period (28 days after PC cell injection) were significantly higher in the PC-3PR group. Data are presented as the mean \pm SD. $(n=6$, $\mathrm{P}<0.05$ ). (D) Ki67 IHC indicated that the proliferation level of the PC-3PR group was higher than that of the PC-3 and PC-3PR mimic group. (E) TUNEL assay indicated that the apoptotic level of PC-3PR cells was lower than that of the PC-3 and PC-3PR mimic groups. ${ }^{*} \mathrm{p}<0.05 ;{ }^{* *} \mathrm{p}<0.01{ }^{* * *} \mathrm{p}<0.001$.

\section{Overexpression of miR-34a is involved in the development of paclitaxel chemosensitivity}

To investigate the role of miR-34a in chemo-resistance, we injected PC cells subcutaneously. Twenty-one days later, we observed lower tumor volumes in tumors with miR-34a overexpression compared with tumors with empty vectors under paclitaxel administration (Fig. 8A and 8B). At the end of experiment period, the mean wet weights of tumors were significantly lower in the miR-34a transfected group than in the empty vector control group ( $<$ 0.05) (Fig. 8C). Furthermore, the Ki67 immunohistochemistry (IHC) and TUNEL assays of xenograft tumors indicated that the proliferation of the PC-3PR group was higher compared with the PC-3 and PC-3PR mimic groups (Fig. 8D and 8E). Clearly, the higher expression of miR-34a is associated with sensitivity to paclitaxel in vivo.

\section{Discussion}

Paclitaxel is a common chemotherapeutic agent used to treat multiple malignancies, including those at the mCRPC stage. However, there are no markers of response or resistance known for paclitaxel. Therefore, the development of new molecules for PC screening and treatment is urgently needed. Molecular profiling of miRNAs may help to develop companion clinical diagnostics to identify subgroups of patients who will respond to this common chemotherapy, and enable a better understanding of the molecular mechanisms of chemoresistance $[23,24]$. There is good evidence to suggest that miRNA regulation of gene expression plays a key role in chemotherapy. By directly targeting protein-coding genes,

\section{KARGER}


miRNAs can inhibit genes that are needed for signaling pathways or drug-induced apoptosis [25]. In recent years, miRNAs have attracted attention in PC [26, 27]. Multiple miRNAs are thought to be critical for the control of drug resistance in PC [25]. In this study, we examined the influence of paclitaxel on miR-34a expression and target genes using in vitro and in vivo assays. Our results indicated that miR-34a contributed to the success of chemotherapy via the JAG1/Notch1 axis in PC cells.

Treatment of mCRPC often fails because of chemoresistance [28, 29]. Previous studies have shown that miR-34a is down-regulated in many types of cancer, and acts as a critical tumor suppressor by targeting multiple oncogenes that modulate cancer-related processes, such as cell proliferation, apoptosis, metastasis, and chemo-resistance [30]. Moreover, previous studies have indicated that miR-34a mediates AR-dependent p53-induced apoptosis [31], and miR-34a inhibits proliferation and metastasis by directly repressing CD44 TCF7, LEF1, and SIRT1 [20, 32-34]. In this study, we obtained PC-3PR from PC-3 through continuous paclitaxel treatment. We performed a series of in vitro and in vivo studies to obtain evidence that the decreased expression of miR-34a significantly contributes to lung and liver metastasis and chemoresistance through the inhibition of apoptosis and the JAG1/Notch1 axis in PC. Accumulating evidence shows that the induction of apoptosis and activation of Notch1 signaling pathways dramatically suppresses tumor growth, metastasis, and chemoresistance, including in PC $[21,35,36]$. Our data clearly showed that the overexpression of miR-34a significantly enhanced paclitaxel-induced apoptosis and Notch1 signaling pathway inhibition and dramatically inhibited PC metastasis in vivo, which indicates that the restoration of miR-34a may be a useful strategy for the treatment of metastasis and chemoresistance, in PC patients.

Notch signaling is an important pathway activated during the development of PC [37]. Notch ligand JAG1 was found to be overexpressed in metastatic PC, in contrast to PC or benign prostatic tissues [38]. Upon further investigation into the potential role of miR-34a in paclitaxel resistance in PC, we performed qRT-PCR and western blot analysis and confirmed an association between decreased miR-34a and increased expression of the two target genes, JAG1 and Notch1. JAG1/Notch1 regulated gene expression in the Notch1 signaling pathway. In this study, we identified JAG1/Notch1 as novel targets of miR-34a genes in PC chemoresistance. Luciferase reporter gene experiments showed that miR-34a directly targeted 3'-UTR of JAG1 and Notch1.

\section{Conclusion}

In conclusion, our data showed that increased miR-34a expression played an important role in resistance to paclitaxel in PC and PC-3 cells. Meanwhile, JAG1 and Notch1, as direct and functional targets of miR-34a, mediated miR-34a-induced chemoresistance to paclitaxel in PC-3 cells. The miR-34a/JAG1/Notch1 axis provides a new avenue that will help us to gain an understanding of the mechanism of chemoresistance, and it may help the development of potential therapeutics for the treatment of PC (Fig. 9).

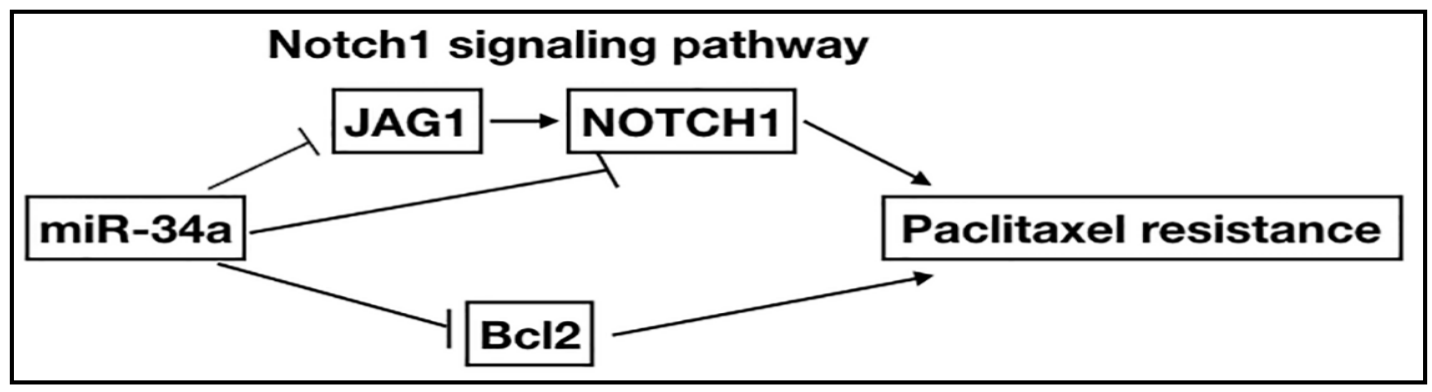

Fig. 9. Schematic of the modelmiR-34a might attenuate PC cell metastasis and chemo-resistance through the JAG1/Notch1 axis. 


\section{Cellular Physiology Cell Physiol Biochem 2018;50:261-276 \begin{tabular}{cl|l} 
DOI: 10.1159/000494004 218 & $\begin{array}{l}\text { O 2018 The Author(s). Published by S. Karger AG, Basel } \\
\text { www.karger.com/cpb }\end{array}$
\end{tabular}}

Liu et al.: microRNA-34a Attenuates Chemoresistance of Prostate Cancer Cells

\section{Acknowledgements}

This work was supported partly by the National Natural Science Foundation of China (81470989), and partly by the clinical research project key projects of Second Affiliated Hospital, Third Military Medical University (2014YLC28 and 2015YLC06). We thank Dr. Fan Yang for the constructive comments and editing the manuscript. We are grateful to the authors and publications that were not cited in this paper due to space restrictions.

\section{Disclosure Statement}

The authors declare that they have no competing interests.

\section{References}

1 Siegel RL, Miller KD, Jemal A: Cancer statistics, 2015. CA Cancer J Clin 2015;65:5-29.

-2 Chen W, Zheng R, Baade PD, Zhang S, Zeng H, Bray F, Jemal A, Yu XQ He J: Cancer statistics in China, 2015. CA Cancer J Clin 2016;66:115-132.

3 Bhatnagar N, Li X, Padi SK, Zhang Q, Tang MS, Guo B: Downregulation of miR-205 and miR-31 confers resistance to chemotherapy-induced apoptosis in prostate cancer cells. Cell Death Dis 2010;1:e105.

4 Berry W, Eisenberger M: Achieving treatment goals for hormone-refractory prostate cancer with chemotherapy. Oncologist 2005;10 Suppl 3:30-39.

-5 Impens F, Van Damme P, Demol H, Van Damme J, Vandekerckhove J, Gevaert K: Mechanistic insight into taxol-induced cell death. Oncogene 2008;27:4580-4591.

-6 Petrylak DP, Tangen CM, Hussain MH, Lara PN Jr, Jones JA, Taplin ME, Burch PA, Berry D, Moinpour C, Kohli M, Benson MC, Small EJ, Raghavan D, Crawford ED: Docetaxel and estramustine compared with mitoxantrone and prednisone for advanced refractory prostate cancer. N Engl J Med 2004;351:1513-1520.

7 Caldas C, Brenton JD: Sizing up miRNAs as cancer genes. Nat Med 2005;11:712-714.

-8 Calin GA, Croce CM: MicroRNA signatures in human cancers. Nat Rev Cancer 2006;6:857-866.

$>9$ Choi N, Park J, Lee JS, Yoe J, Park GY, Kim E, Jeon H, Cho YM, Roh TY, Lee Y: miR-93/miR-106b/miR-375-CICCRABP1: a novel regulatory axis in prostate cancer progression. Oncotarget 2015;6:23533-23547.

10 Fang L, Li H, Wang L, Hu J, Jin T, Wang J, Yang BB: MicroRNA-17-5p promotes chemotherapeutic drug resistance and tumour metastasis of colorectal cancer by repressing PTEN expression. Oncotarget 2014;5:2974-2987.

11 Rokavec M, Oner MG, Li H, Jackstadt R, Jiang L, Lodygin D, Kaller M, Horst D, Ziegler PK, Schwitalla S, SlottaHuspenina J, Bader FG, Greten FR, Hermeking H: IL-6R/STAT3/miR-34a feedback loop promotes EMTmediated colorectal cancer invasion and metastasis. J Clin Invest 2014;124:1853-1867.

-12 Fujita Y, Kojima K, Ohhashi R, Hamada N, Nozawa Y, Kitamoto A, Sato A, Kondo S, Kojima T, Deguchi T, Ito M: MiR-148a attenuates paclitaxel resistance of hormone-refractory, drug-resistant prostate cancer PC3 cells by regulating MSK1 expression. J Biol Chem 2010;285:19076-19084.

13 Puhr M, Hoefer J, Schafer G, Erb HH, Oh SJ, Klocker H, Heidegger I, Neuwirt H, Culig Z: Epithelial-tomesenchymal transition leads to docetaxel resistance in prostate cancer and is mediated by reduced expression of miR-200c and miR-205. Am J Pathol 2012;181:2188-2201.

14 Shi GH, Ye DW, Yao XD, Zhang SL, Dai B, Zhang HL, Shen YJ, Zhu Y, Zhu YP, Xiao WJ, Ma CG: Involvement of microRNA-21 in mediating chemo-resistance to docetaxel in androgen-independent prostate cancer PC3 cells. Acta Pharmacol Sin 2010;31:867-873.

15 Kojima K, Fujita Y, Nozawa Y, Deguchi T, Ito M: MiR-34a attenuates paclitaxel-resistance of hormonerefractory prostate cancer PC3 cells through direct and indirect mechanisms. Prostate 2010;70:1501-1512.

-16 Wang Y, Lieberman R, Pan J, Zhang Q Du M, Zhang P, Nevalainen M, Kohli M, Shenoy NK, Meng H, You M, Wang L: miR-375 induces docetaxel resistance in prostate cancer by targeting SEC23A and YAP1. Mol Cancer 2016;15:70. 


\section{Cellular Physiology Cell Physiol Biochem 2018;50:261-276



Liu et al.: microRNA-34a Attenuates Chemoresistance of Prostate Cancer Cells

17 Corcoran C, Rani S, O’Driscoll L: miR-34a is an intracellular and exosomal predictive biomarker for response to docetaxel with clinical relevance to prostate cancer progression. Prostate 2014;74:1320-1334.

18 Watahiki A, Wang Y, Morris J, Dennis K, O’Dwyer HM, Gleave M, Gout PW, Wang Y: MicroRNAs associated with metastatic prostate cancer. PloS One 2011;6:e24950.

19 Kang L, Mao J, Tao Y, Song B, Ma W, Lu Y, Zhao L, Li J, Yang B, Li L: MicroRNA-34a suppresses the breast cancer stem cell-like characteristics by downregulating Notch1 pathway. Cancer Sci 2015;106:700-708.

20 Duan K, Ge YC, Zhang XP, Wu SY, Feng JS, Chen SL, Zhang LI, Yuan ZH, Fu CH: miR-34a inhibits cell proliferation in prostate cancer by downregulation of SIRT1 expression. Oncology Lett 2015;10:32233227.

21 Liu C, Li Z, Bi L, Li K, Zhou B, Xu C, Huang J, Xu K: NOTCH1 signaling promotes chemoresistance via regulating ABCC1 expression in prostate cancer stem cells. Mol Cell Biochem 2014;393:265-270.

22 O’Brien R, Marignol L: The Notch-1 receptor in prostate tumorigenesis. Cancer Treat Rev 2017;56:36-46. Kanwal R, Plaga AR, Liu X, Shukla GC, Gupta S: MicroRNAs in prostate cancer: Functional role as biomarkers. Cancer Lett 2017;407:9-20.

24 Kopczynska E: Role of microRNAs in the resistance of prostate cancer to docetaxel and paclitaxel. Contemp Oncol (Pozn) 2015;19:423-427.

25 Li F, Mahato RI: MicroRNAs and drug resistance in prostate cancers. Mol Pharm 2014;11:2539-2552.

26 Du Y, Liu XH, Zhu HC, Wang L, Ning JZ, Xiao CC: MiR-543 Promotes Proliferation and EpithelialMesenchymal Transition in Prostate Cancer via Targeting RKIP. Cell Physiol Biochem 2017;41:1135-1146.

-27 Pang C, Liu M, Fang W, Guo J, Zhang Z, Wu P, Zhang Y, Wang J: MiR-139-5p is Increased in the Peripheral Blood of Patients with Prostate Cancer. Cell Physiol Biochem 2016;39:1111-1117.

28 Beltran H, Wyatt AW, Chedgy E, Donoghue A, Annala M, Warner E, Beja K, Sigouros M, Mo F, Fazli L, Collins CC, Eastham JA, Morris MJ, Taplin ME, Sboner A, Halabi S, Gleave ME: Impact of therapy on genomics and transcriptomics in high-risk prostate cancer treated with neoadjuvant docetaxel and androgen deprivation therapy. Clin Cancer Res 2017;23:6802-6811.

29 de Bono JS, Chowdhury S, Feyerabend S, Elliott T, Grande E, Melhem-Bertrandt A, Baron B, Hirmand M, Werbrouck P, Fizazi K: Antitumour activity and safety of enzalutamide in patients with metastatic castration-resistant prostate cancer previously treated with abiraterone acetate plus prednisone for $>/=24$ weeks in Europe. Eur Urol 2018;74:37-45.

-30 Ghandadi M, Sahebkar A: MicroRNA-34a and its target genes: Key factors in cancer multidrug resistance. Curr Pharm Des 2016;22:933-939.

31 Rokhlin OW, Scheinker VS, Taghiyev AF, Bumcrot D, Glover RA, Cohen MB: MicroRNA-34 mediates ARdependent p53-induced apoptosis in prostate cancer. Cancer Biol Ther 2008;7:1288-1296.

32 Chen WY, Liu SY, Chang YS, Yin JJ, Yeh HL, Mouhieddine TH, Hadadeh O, Abou-Kheir W, Liu YN: MicroRNA34a regulates WNT/TCF7 signaling and inhibits bone metastasis in Ras-activated prostate cancer. Oncotarget 2015;6:441-457.

-33 Liang J, Li Y, Daniels G, Sfanos K, De Marzo A, Wei J, Li X, Chen W, Wang J, Zhong X, Melamed J, Zhao J, Lee P: LEF1 targeting EMT in prostate cancer invasion is regulated by miR-34a. Mol Cancer Res 2015;13:681-688.

-34 Liu C, Kelnar K, Liu B, Chen X, Calhoun-Davis T, Li H, Patrawala L, Yan H, Jeter C, Honorio S, Wiggins JF, Bader AG, Fagin R, Brown D, Tang DG: The microRNA miR-34a inhibits prostate cancer stem cells and metastasis by directly repressing CD44. Nat Med 2011;17:211-215.

-35 Symonds H, Krall L, Remington L, Saenz-Robles M, Lowe S, Jacks T, Van Dyke T: p53-dependent apoptosis suppresses tumor growth and progression in vivo. Cell 1994;78:703-711.

-36 Xiao W, Gao Z, Duan Y, Yuan W, Ke Y: Notch signaling plays a crucial role in cancer stem-like cells maintaining stemness and mediating chemotaxis in renal cell carcinoma. J Exp Clin Cancer Res 2017;36:41.

37 Villaronga MA, Bevan CL, Belandia B: Notch signaling: a potential therapeutic target in prostate cancer. Curr Cancer Drug Targets 2008;8:566.

-38 Wang Z, Li Y, Banerjee S, Kong D, Ahmad A, Nogueira V, Hay N, Sarkar FH: Down-regulation of Notch-1 and Jagged-1 inhibits prostate cancer cell growth, migration and invasion, and induces apoptosis via inactivation of Akt, mTOR, and NF-kappaB signaling pathways. J Cell Biochem 2010;109:726-736. 